\title{
TERAPIA GÉNICA CONTRA LA RETINOSIS PIGMENTARIA
}

\section{GENE THERAPY AGAINST RETINOSIS PIGMENTARY}

\author{
VECINO $E^{1}$
}

La retinosis pigmentaria ha sido una de las patologías oculares desconocida durante mucho tiempo, y cuando hemos empezado a conocerla, nos hemos dado cuenta de lo compleja que es. Esta complejidad viene dada por la diversidad de mutaciones que pueden causarla y la diferente progresión en su avance, lo que hace impredecible cuándo se manifestará de forma más severa.

Uno de los retrasos en el conocimiento preciso de la enfermedad ha sido, como en muchas otras patologías, la falta de modelos animales donde estudiar las causas y mecanismos de avance de la enfermedad. Los mejores modelos animales, sin duda, son aquellos donde la enfermedad se manifiesta de forma natural y, gracias a los oftalmólogos veterinarios, se pudo diagnosticar la enfermedad en perros. La investigación en estos animales mostró que la retinosis en los perros se manifiesta de muy diversas formas, al igual que en humanos, con la presencia de mutaciones equivalentes a las de los humanos (Aguirre et al., 1978) (1). Paradójicamente, los perros, que sirven de guía a los afectados por la retinosis, han servido también de guías a los investigadores para conocer las causas que inducen esta enfermedad.

Durante años se han estudiado los perros afectados con todo lujo de detalles moleculares, celulares, oftalmológicos y de comportamiento, para poder llegar a las únicas terapias contra la retinosis que se están probando en la actualidad. Así, en los años noventa se realizaron los primeros ensayos clínicos con terapia génica y células encapsuladas en perros, dando resultados muy positivos que permitieron que la FDA diera luz verde para comenzar con los ensayos clínicos en humanos. Las terapias que en la actualidad se están desarrollando en humanos han tenido su origen en los estudios desarrollados por el grupo dirigido por el Dr. Gustavo Aguirre de la Universidad de Pensilvania con células encapsuladas (Tao et al., 2002) (2) y con terapia génica (Acland et al., 2001) (3).

En la actualidad existen dos terapias en fase de ensayo clínico contra la retinosis pigmentaria en humanos. En fase II se encuentra el ensayo clínico utilizando células encapsuladas modificadas para que liberen factores tróficos, en particular el (CNTF) y la terapia génica con virus adeno-asociados portadores del gen correcto que codifica para la proteína RPE65 se encuentra en fase I. Esta mutación da origen a un tipo de amaurosis congénita de Leber. Si los resultados de estos ensayos que originariamente comenzaron el pasado mes de mayo en Inglaterra, dieran resultados positivos, estaríamos ante la primera terapia efectiva a la carta contra un tipo de mutación en la retina que podría continuar con el tratamiento de otras mutaciones y así poderla aplicar a otras mutaciones en genes implicados en la retinosis pigmentaria.

La terapia génica con virus adenoasociados AAV portadores del gen que corregirá la mutación causante de la enfermedad abre las puertas a «la terapia a la carta» tan esperada en esta «enfermedad rara» que es la retinosis pigmentaria. En un reciente editorial de la prestigiosa revista de investigación Nature, mencionan las estadísticas sobre el tipo de estrategia molecular que se ha utilizado en los ensayos clínicos realizados con terapia génica para distintas enfermedades, así de los 284 ensayos clínicos, el 4\% se ha realizado utilizando virus adenoasociados AAV (como en el caso de la terapia del RP65) y en ningún caso se han visto efectos adversos.

Los estudios realizados por el grupo del Dr. Aguirre, que han dado como fruto el comienzo de la

\footnotetext{
1 Catedrática de Biología Celular. Universidad del País Vasco. España. E-mail: elena.vecino@ehu.es
} 
terapia génica en humanos, demostraron la restauración de la función visual en los animales tratados con terapia génica (Acland et al., 2005) (4). En una reciente colaboración con su grupo, y gracias a la financiación de FUNDALUCE y la Fundación ONCE, hemos tenido la oportunidad de estudiar las retinas de perros tratados con terapia génica en los que se había ya demostrado la restauración de la función visual, comprobando que tras la terapia génica con RPE65-AAV, la estructura y distribución molecular de la retina también se restaura casi en su totalidad (Hernández et al., 2007) (5).

Sin duda el gran reto en estos momentos es conocer el tipo de mutación que tienen los afectados por esta enfermedad, con el fin de realizar un mapa internacional del número de afectados con la misma mutación. En estos momentos existen algunas instituciones que realizan la identificación de la mutación de los afectados. De momento, se oferta la identificación en el caso de que los pacientes tengan una mutación conocida, ya que la caracterización de nuevas mutaciones necesitaría un trabajo de varios años de dedicación, que no obstante, algunos grupos de investigación lo están realizando en la actualidad. Sin duda este es uno de los retos de los próximos años y el esfuerzo para conseguirlo no debería de originarse tan solo en los pacientes, que están más que motivados, sino en las instituciones, que mediante partidas presupuestarias especiales, permitieran organizar el genotipado de la población afectada por retinosis, así como el continuo apoyo a la investigación en el campo de las enfermedades raras, ya iniciado en los últimos años.

Tras más de treinta años de investigación, la terapia contra la retinosis está más cercana, pero es necesario ir con cautela y sin precipitaciones. Esperar a la comunicación de los resultados de los primeros pacientes es fundamental, con el fin de poder perfeccionar al máximo el tratamiento antes de efectuarlo de forma rutinaria.

\section{BIBLIOGRAFÍA}

1. Aguirre GD, Farber D, Lolley R, Fletcher RT, Chader G. Rod-cone dysplasia in Irish setter: a defect in cyclic GMP metabolism in visual cells. Science 1978; 201: 1133-1134.

2. Tao W, Wen R, Goddard MB, Sherman SD, O'Rourke PJ, Stabila PF, et al. Encapsulated cell-based delivery of CNTF reduces photoreceptor degeneration in animal models of retinitis pigmentosa. Invest Ophthalmol Vis Sci 2002; 43: 3292-3298.

3. Acland GM, Aguirre GD, Ray J, Zhang Q, Aleman TS, Cideciyan AV, et al. Gene therapy restores vision in a canine model of childhood blindness. Nat Genet 2001; 28: 92-95.

4. Acland GM, Aguirre GD, Bennett J, Aleman TS, Cideciyan $A V$, Bennicelli $J$, et al. Long-term restoration of rod and cone vision by single dose $r A A V$-mediated gene transfer to the retina in a canine model of childhood blindness. Mol Ther 2005; 12: 1072-1082.

5. Hernandez M, Rivas A, Pearce-Kelling SE, Acland GM, Rodriguez D, Aguirre $G$, et al. Recovery of molecular marker expression in RPE65 mutant dog retinas after gene therapy using Adeno-Associated virus. ARVO 2007; 4616/B453. 